\title{
Cocción tradicional con especias de Phaseolus vulgaris L. y su efecto antinutricional e inhibición bacteriana
}

\author{
Traditional cooking with spices from Phaseolus vulgaris L. and its antinutritional effect \\ and bacterial inhibition
}

\begin{abstract}
Alexis Lamz Piedra', Zulema Cázares Chávez², José Cruz Jiménez Galindo ${ }^{3}$, Francisco Javier Molina Corral ${ }^{4}$, David Roberto Sepúlveda Ahumada ${ }^{4}$, Claudio Rios-Velasco4, Guadalupe Isela Olivas Orozco ${ }^{4 *}$

Departamento de Genética y Mejoramiento de las Plantas. Instituto Nacional de Ciencias Agrícolas, La Habana, Cuba

2 Facultad de Ciencias Químicas, Universidad Autónoma de Chihuahua. Circuito Universitario Campus II. CP 31125, Chihuahua, Chih., México

3 Instituto Nacional de Investigaciones Forestales, Agrícolas y Pecuarias. Av. Hidalgo 1213, Col. Centro, Cd. Cuauhtémoc, Chih, México

Centro de Investigación en Alimentación y Desarrollo A.C., Av. Rio Conchos S/N, CP 31570, Cuauhtémoc, Chih., México.
\end{abstract}

\section{RESUMEN}

El frijol ha sido un alimento importante para los mexicanos desde tiempos ancestrales. En el pasado, los frijoles eran cocinados en ollas de barro agregando especias (epazote o laurel). En la actualidad, las ollas de presión han remplazado a las de barro y el uso de especias es casi una tradición perdida. Para comprender los métodos tradicionales de cocción, el presente trabajo evaluó el efecto de la adición de especias (laurel o epazote) y del método de cocción (olla de barro o de presión), sobre las características antinutricionales y la inhibición bacteriana. Los resultados muestran que los métodos tradicionales, olla de barro, adición de epazote y laurel, así como el remojo, disminuyen considerablemente la concentración de a-oligosacáridos. Mientras que la cocción en olla de presión con previo remojo, disminuye en mayor proporción la concentración de ácido fítico y reduce la actividad de los compuestos inhibidores de tripsina. Por otro lado, el uso de especias inhibe el crecimiento microbiano. Una combinación de cocina tradicional mexicana (remojo y uso de especias) y cocina moderna (olla a presión) disminuye los compuestos antinutricionales y conserva la calidad microbiana de los frijoles. Estos resultados muestran la importancia de estudiar y preservar la cocina tradicional mexicana.

Palabras clave: Frijol, oligosacáridos, ácido fítico, laurel, epazote

\section{ABSTRACT}

Beans have been an essential food for mexicans since ancient times. In the past, beans were cooked in clay pots with spices (epazote or bay leaf) added. Today, pressure cookers have replaced clay cookers, and herbs are almost a lost tradition. To understand traditional cooking methods, the present work evaluated the effect of the addition of spices (laurel or epazote) and the cooking method (clay pot or pressure cooker), on antinutritional characteristics and bacterial inhibition. The results show that the traditional techniques, clay pot, spices addition (epazote and bay leaf), and soaking, considerably decrease the concentration of

\section{Volumen XXIII, Número 1}

a-oligosaccharides. On the other hand, when cooking in a pressure cooker with previous soaking, the concentration of phytic acid decreases to a greater extent, and reduces the activity of trypsin inhibitor compounds. On the other hand, the use of spices inhibits microbial growth. A combination of traditional Mexican cuisine (soaking and herbs usage) and modern cuisine (pressure cooker) decreases antinutritional compounds and preserves the beans' microbial quality. These results show the importance of studying and maintaining traditional Mexican cuisine.

Keywords: Beans, phytic acid, oligosacharides, bay leaf, epazote

\section{INTRODUCCIÓN}

El frijol común (Phaseolus vulgaris L.) forma parte importante de la dieta del ser humano en muchos países del mundo, especialmente en África, India y Centroamérica (Xu y Chang, 2009, Chávez-Mendoza et al., 2019). En México, los frijoles han sido importantes constituyentes de la dieta, por su valor nutricional que incluye altos niveles de proteína, fibra dietética, almidón resistente, ácido a-linolénico y micronutrientes como: hierro, zinc, entre otros (Hayat et al., 2014; Lo Turco et al., 2016; Gomes Basso Los et al., 2018; Corzo-Ríos et al., 2020). Además, los frijoles contienen compuestos bioactivos con propiedades benéficas para la salud, entre estos: ácidos fenólicos, flavonoles, isoflavonas, taninos, antocianinas y procianidinas (Chávez-Mendoza et al., 2019; Parmar et al., 2017; Xu y Chang, 2009). En años recientes se ha encontrado evidencia del efecto positivo del consumo de esta leguminosa en la prevención de enfermedades y en la promoción de la salud; y se le ha considerado un tratamiento efectivo para la prevención y control de obesidad, diabetes, enfermedades cardiovasculares y cáncer (Ulloa et al., 2011; Hayat et al., 2014; Gomes Basso Los et al., 2018; Pérez-Ramírez et al., 2018; Armendáriz-Fernández et al., 2019).

Sin embargo, los frijoles contienen algunos constituyentes antinutricionales, tales como: los compuestos inhibidores de tripsina y los fitatos, los cuales pueden reducir la biodisponibilidad de nutrientes, además de los a-galacto-

*Autor para correspondencia: Guadalupe Isela Olivas Orozco Correo electrónico: golivas@ciad.mx

Recibido: 21 de julio de 2020 Aceptado: 11 de octubre de 2020 
oligosacáridos, causantes de inflamación abdominal y flatulencias. Los inhibidores de tripsina son proteínas de bajo peso molecular capaces de ligar la tripsina, enzima peptidasa digestiva, impidiendo la hidrólisis de proteínas y la absorción de aminoácidos (Wang et al., 2010). Los fitatos reducen la biodisponibilidad de minerales esenciales al funcionar como quelantes de metales catiónicos como el zinc, el fierro, el calcio y el magnesio (Parmar et al., 2017). La remoción de estos componentes mejora la calidad nutricional del frijol (Machaiah y Pednekar, 2002). Una de las principales causas disuasorias para el consumo de frijol son los a-galactooligosacáridos (Aguilera et al., 2009). Debido a la ausencia de la enzima a-galactosidasa en el organismo humano, estos compuestos no son hidrolizados en la parte superior del tracto gastrointestinal, siendo posteriormente fermentados por la microbiota del colon, con la consecuente producción de gases (dióxido de carbono, hidrógeno y metano) y generación de inflamación y flatulencias (Njoumi et al., 2019).

Para disminuir la concentración de los componentes antinutricionales, es necesario el procesamiento térmico de los frijoles. La cocción es probablemente el tratamiento más antiguo y más utilizado de procesamiento de frijoles (Revilla, 2015). Sin embargo, en México, la manera de cocinar el frijol ha cambiado con el tiempo. En el pasado los frijoles eran cocinados en olla de barro usando especias como epazote (Chenopodium ambrosioides), o laurel (Laurus nobilis), con la creencia de que estas hierbas disminuían los problemas de flatulencia en los consumidores. En la actualidad, la acelerada transformación de las prácticas alimentarias; expresada por la disminución en el tiempo dedicado a la elaboración y al consumo de los alimentos (Meléndez y Cañez, 2009), ha fomentado el uso de ollas de presión, que disminuyen el tiempo de cocción de los alimentos; dejando a un lado el uso tradicional de las ollas de barro. Igualmente, el uso de especias ha sido prácticamente olvidado como efecto de la globalización, que ha llevado a la pérdida de las raíces culinarias (Leyva y Pérez, 2015); todo esto en menoscabo de nuestras tradiciones ancestrales, sin haber antes estudiado $y$ comprendido la relevancia de lo que se está perdiendo. Por lo anterior el presente estudio tuvo como objetivo evaluar el efecto de la cocción del frijol por métodos tradicionales sobre los factores antinutricionales del frijol Pinto Saltillo (Phaseolus vulgaris); evaluando la cocción en olla de barro o a presión, el empleo de remojo, así como el uso de hojas de laurel (Laurus nobilis) o epazote (Chenopodium ambrosioides).

\section{MATERIALES Y MÉTODOS}

La investigación se llevó a cabo en el Centro de Investigación en Alimentación y Desarrollo (CIAD), unidad Cuauhtémoc, Chihuahua, México. Para el estudio se empleó frijol (Phaseolus vulgaris L.) de la variedad 'Pinto Saltillo' cultivado en la región de Namiquipa, Chihuahua. Para la realización de todas las determinaciones se utilizó una cantidad de $42 \mathrm{Kg}$ aproximadamente de frijol.

\section{Preparación del frijol}

El frijol fue sometido a los siguientes tratamientos: con remojo y sin remojo previo a la cocción, cocción con adicción de epazote, laurel o sin especias (control); y cocción en olla de barro o en olla de presión. Para la preparación de los frijoles cocidos se pesaron y lavaron $150 \mathrm{~g}$ de frijol por tratamiento. El frijol con remojo se sometió a inmersión en $1000 \mathrm{~mL}$ de agua a temperatura ambiente durante 12 horas. El frijol sometido al tratamiento de cocción en olla a presión se cocinó con un litro de agua durante 45 minutos a temperatura de $121^{\circ} \mathrm{C}$, y el destinado a tratamiento en olla de barro se cocinó con dos litros de agua durante 3 horas a $96^{\circ} \mathrm{C}$. Antes de la cocción, epazote fresco $(0.39 \mathrm{~g})$, laurel seco $(0.07 \mathrm{~g})$, o ninguna especia fueron adicionadas. Los frijoles en combinación con el caldo de la cocción fueron enfriados a temperatura ambiente y homogenizados para su posterior análisis.

\section{Determinación del contenido de ácido fítico}

El contenido de fitatos se determinó mediante el método reportado por Al-Kaisey et al. (2003). Para el frijol cocido en olla de barro se tomó una muestra de $6 \mathrm{~g}$ de frijol y $6 \mathrm{~mL}$ de caldo; para el frijol cocido en olla a presión se pesaron $6 \mathrm{~g}$ de frijol y $12 \mathrm{~mL}$ de caldo (cantidades de agua proporcionales al agua restante después de cocción). La absorbancia fue medida a $830 \mathrm{~nm}$ (Espectrofotómetro UV-VIS marca Varian, modelo Cary, Walnut Creek, CA, EUA), para determinar el contenido de fósforo insoluble en la sal férrica. Los valores de absorbancia de las muestras obtenidos en el espectrofotómetro se interpolaron en una curva de calibración construida utilizando ácido fítico como estándar (Sigma-Aldrich), en concentraciones entre 0 y $10 \mathrm{mg} / \mathrm{g}$. El ácido fítico fue calculado asumiendo que contiene $28.2 \%$ de fósforo (Al-Kaisey et al., 2003). El contenido de ácido fítico fue expresado en $\mathrm{mg} / \mathrm{g}$ de materia seca.

\section{Determinación del contenido de oligosacáridos (rafino- sa, estaquiosa y verbascosa)}

El contenido de oligosacáridos fue determinado por el método de Sánchez-Mata et al. (1998), utilizando una mezcla de $4.5 \mathrm{~g}$ de frijol cocido mezclados con $4.5 \mathrm{ml}$ de caldo para el tratamiento de cocción en olla de barro, y $4.5 \mathrm{~g}$ de frijol y $9 \mathrm{~g}$ de agua para el tratamiento de cocción en olla de presión (cantidades de agua proporcionales al agua restante después del proceso cocción). Las muestras se analizaron por HPLC (Varian, modelo 9012 Q, EUA), utilizando una columna YMC PBMN de $5 \mu \mathrm{m}, 4.6 \times 250 \mathrm{~mm}$ y $120 \AA$ (WATERS, PB12S052546WT, EUA), con detector de índice de refracción $(32 \times 10.6$ RIU/FS), y acetonitrilo-agua 60:40 como fase móvil con un flujo de $1 \mathrm{~mL} / \mathrm{min}$. Los valores obtenidos fueron interpolados en las curvas de calibración, las cuales se realizaron utilizando estándares ultrapuros de rafinosa, estaquiosa y verbascosa (Fluka). El contenido de estos oligosacáridos fue expresado en $\mathrm{mg} / \mathrm{g}$ de materia seca. 


\section{Contenido de inhibidor de tripsina}

El contenido de inhibidor de tripsina se determinó colorimétricamente siguiendo el método descrito por Hamerstrand et al. (1981), utilizando un espectrofotómetro (UV-VIS marca Varian, modelo Cary, Walnut Creek, CA, EUA) a $392 \mathrm{~nm}$ contra el blanco. La muestra de frijol cocido utilizada fue una mezcla de $3 \mathrm{~g}$ de frijol y $3 \mathrm{~mL}$ de caldo de cocción, para el tratamiento en olla de barro; mientras que para el tratamiento en olla de presión la muestra consistió en una mezcla de $3 \mathrm{~g}$ de frijol y $6 \mathrm{~mL}$ de caldo de cocción.

\section{Análisis microbiológico}

Para evaluar el desarrollo microbiano de la bacteria Pseudomona alcalígenes una muestra de frijol cocido de cada tratamiento $(150 \mathrm{~mL}$ de caldo de cocción y $150 \mathrm{~g}$ de frijol cocido) fue homogeneizada con un equipo Stomacher (IUL, modelo 181/520, EUA) durante 90 segundos y posteriormente inoculada con $100 \mu \mathrm{L}$ de suspensión bacteriana conteniendo $1 \times 10^{\circ} \mathrm{UFC}$. El homogeneizado de frijol se almacenó a $4^{\circ} \mathrm{C}$ y se muestreó diariamente por un periodo de cinco días para determinar la carga psicotrófica, preparando diluciones seriadas en agua peptonada, las cuales se sembraron en cajas Petri con agar Pseudomona y se incubaron a $28^{\circ} \mathrm{C}$ durante 24 horas, para realizar el conteo microbiano.

\section{Diseño experimental y análisis estadístico}

Se estableció un diseño experimental factorial con tres repeticiones por tratamiento y tres factores que se definieron en la cocción del frijol (olla a presión y olla de barro), remojo (con y sin remojo) y adición de especias (laurel, epazote y control). Luego de comprobar los supuestos teóricos normalidad y homogeneidad de varianza, los datos fueron analizados mediante un análisis de varianza factorial y las diferencias significativas entre tratamientos se verificaron por la prueba de rango múltiple de Tukey $p \leq 0.05$ con el paquete estadístico SAS 9.3 (SAS Institute, 2016).

\section{RESULTADOS Y DISCUSIÓN Ácido fítico}

El análisis de varianza del ácido fítico muestra diferencias estadísticamente significativas $(P<0.05)$ en los factores de remojo, cocción y en la doble interacción de remojo-cocción y especias-cocción. No se observó efecto significativo del uso de especias en la disminución del contenido de ácido fítico y así mismo, no se detectaron diferencias estadísticas en la triple interacción remojo-especias-cocción ( $p>0.05$ ).

En la Figura 1 se puede apreciar el efecto de los factores y de la interacción entre ellos. Se obtuvieron resultados muy claros, los cuales muestran como la cocción en olla a presión ejerce un mayor efecto en la disminución del ácido fítico. Sin embargo, esta disminución fue más marcada cuando existe un previo remojo (en promedio $4.2 \mathrm{mg} / \mathrm{g}$ y $5.7 \mathrm{mg} / \mathrm{g}$, respectivamente). La Figura 1 muestra como la cocción bajo presión por si sola es capaz de disminuir el contenido de este factor antinutricional siendo esta la forma de preparación del frijol más adoptada en la actualidad en las diferentes comu-

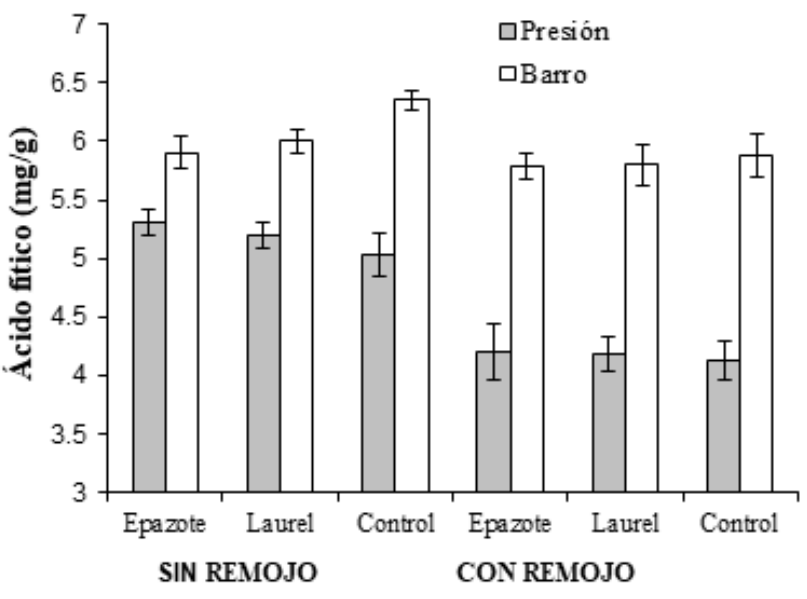

Figura 1. Efecto del remojo, del uso de especias (laurel y epazote) y del método de cocción (olla a presión o de barro) sobre la concentración de ácido fítico en frijol 'Pinto Saltillo' (mg/g base seca). Las barras en las columnas indican la desviación estándar de tres repeticiones por tratamiento para $\mathrm{P}<0.05$.

Figure 1. Effect of soaking, use of spices (bay leaf and epazote), and cooking method (pressure cooker or clay), on the concentration of phytic acid in 'Pinto Saltillo' beans (mg / g dry base). Bars indicate the standard deviation of three repetitions per treatment for $\mathrm{P}<0.05$.

nidades, así como en la industria para la preparación de frijol precocido (Revilla, 2015).

También se pudo apreciar que el contenido de fitatos en la combinación especia-cocción en olla de barro y sin remojo fue significativamente menor ( $p \leq 0.05)$; es decir, cuando el frijol es cocido en olla de barro sin remojo el uso de estas especias disminuiría la concentración de este antinutriente (Figura 1), lo que realza el valor de estas especias que tradicionalmente han sido empleadas por los pobladores de México pudiendo mejorar la disponibilidad de minerales importantes en la nutrición humana.

Aunque no se han detallado los posibles cambios provocados por el uso de la presión en la cocción de leguminosas, varios autores concuerdan en el efecto beneficioso de este método en la disminución del contenido de ácido fítico y otros factores antinutricionales durante la preparación de leguminosas de forma general, posiblemente, se atribuya a cambios en la estructura química de estos compuestos. De acuerdo con Carter y Manthey (2019) la cocción promueve cambios estructurales en la superficie de la cubierta de semillas y el interior de estas. Al respecto, Rehman y Shah (2005) informaron que al incrementar la temperatura en cocción a presión hasta $121^{\circ} \mathrm{C}$ por 90 minutos y a $128^{\circ} \mathrm{C}$ por 20 minutos el contenido de ácido fitico disminuye de $28.0-51.6 \%$ respecto a la cocción ordinaria. Las investigaciones de Kon (1979), refieren que con la cocción a presión se ejerce un mayor rompimiento de algunas células del frijol donde se incluyen los nutrientes y antinutrientes, los cuales se liberan al medio de cocción y consecuentemente se produce una reducción de ácido fítico en la leguminosa. Lo anterior concuerda con las afirmaciones de Grewal y Jood (2006) que atribuyen a este fenómeno a la destrucción de éste factor antinutricional por el tratamiento térmico. 
El remojo disminuyó considerablemente la concentración de ácido fítico en el frijol (Figura 1). Alonso et al. (2000), reportan una reducción significativa en la concentración de ácido fítico después de someter el frijol a un remojo por 12 horas. La reducción en ácido fítico por el remojo ha sido explicada por diferentes investigadores que afirman es el resultado de un efecto de drenaje durante la hidratación (Beleia et al., 1993). Lo anterior concuerda con Grewal y Jood (2006) quienes refieren que la pérdida de ácido fítico en las semillas remojadas se debe a la lixiviación de los iones de fitato dentro del agua por la influencia de la concentración de gradiente (diferencia en el potencial químico) lo cual gobierna la velocidad de difusión. Otras investigaciones concuerdan en que la pérdida de ácido fítico podría también atribuirse a la difusión del agua de remojo a la semilla de frijol lo que podría causar un incremento en la actividad de las fitasas presentes en las leguminosas (Udensi et al., 2007) ya que, de acuerdo con Eskin y Wibe (1983) hay un aumento en la actividad de las fitasas al disminuir el nivel de fitatos como resultado de la hidratación en frijol faba.

Los resultados antes planteados indican que la cocción en barro puede limitar, en mayor medida la disponibilidad de minerales importantes para la nutrición humana, como $\mathrm{Ca}, \mathrm{Fe}, \mathrm{Mg}$ y $\mathrm{Zn}$; por un mayor contenido de ácido fítico en cada porción de frijol consumido, ya que cuando un mineral se une al ácido fítico se vuelve insoluble, precipita y no se absorberá en el intestino, contribuyendo a desarrollar deficiencias de minerales en las personas que utilizan la olla de barro para la cocción de frijol. Esto puede ser un importante problema para las poblaciones de países en vía al desarrollo, sobre todo en los países del continente americano y en África donde el frijol es un alimento básico y constituye una fuente importante de proteínas y minerales (Escalante-Estrada et al., 2014).

\section{Oligosacáridos}

Rafinosa, estaquiosa y verbascosa son los a-galactooligosacáridos encontrados comúnmente en las leguminosas (Gomes Basso Los et al., 2018). En el presente trabajo, el frijol 'Pinto Saltillo' solo presentó rafinosa y estaquiosa; no detectándose verbascosa. Estos resultados concuerdan con Pérez-Ramírez et al. (2018) quienes no obtuvieron verbascosa en frijol de esta misma variedad.

Los factores remojo, especia y cocción de frijol afectaron significativamente la concentración de los oligosacáridos rafinosa y estaquiosa ( $p \leq 0.05)$. En la Figura 2 se puede observar claramente el efecto positivo de todos los factores sobre la disminución de los a-galacto-oligosacáridos, siendo el remojo el factor que disminuyó en mayor proporción el contenido de ambos compuestos (Figura 2), lo que concuerda con Shimelis y Rakshit (2007) en frijol común y con Talari et al. (2018) y Jood et al. (1985) quienes encontraron que el contenido de los oligosacáridos tanto rafinosa como estaquiosa en diferentes leguminosas se reduce altamente cuando son remojadas, de manera proporcional al tiempo de remojo. Favorablemente, el carácter soluble en agua de
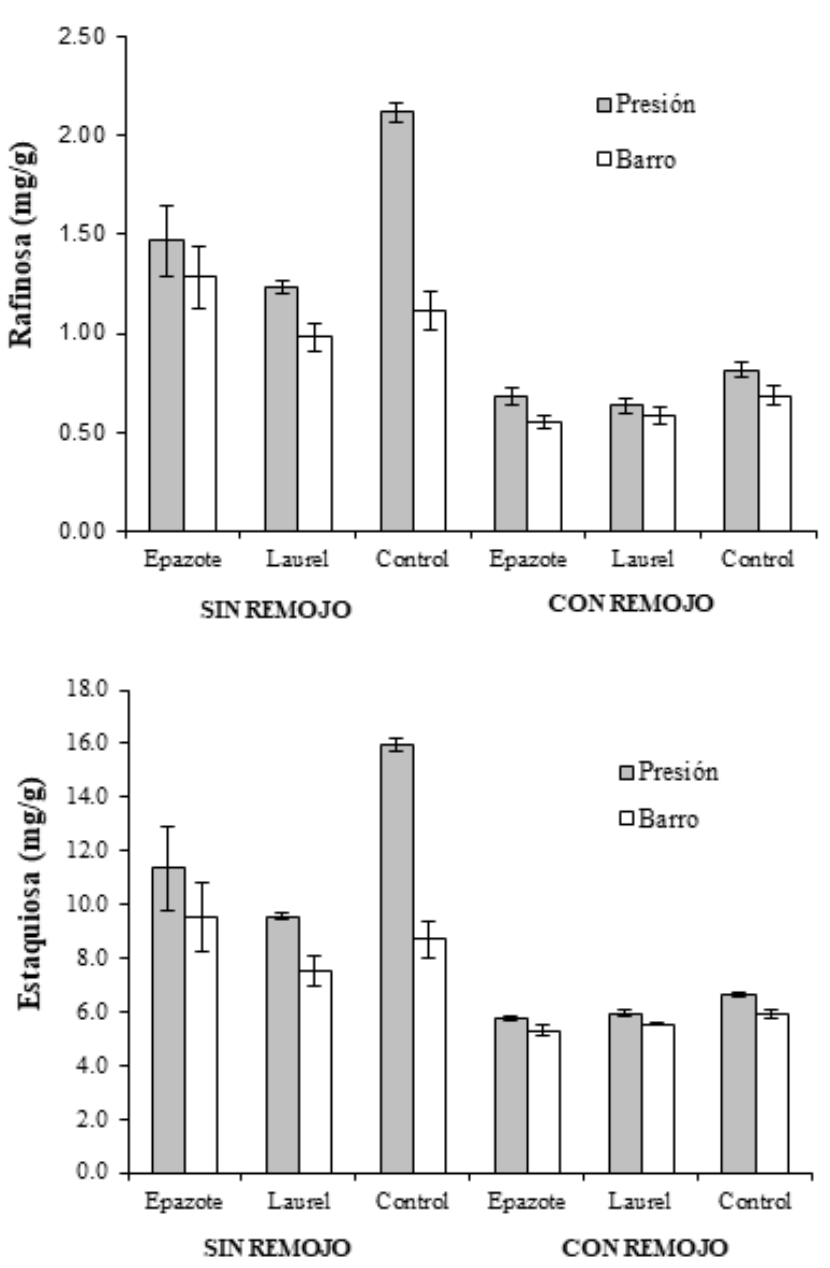

Figura 2. Efecto del remojo, uso de especias (laurel y epazote) y método de cocción (olla a presión o de barro), en la concentración de a-galactooligosacáridos rafinosa (A) y estaquiosa (B) en frijol 'Pinto Saltillo' (mg/g base seca). Las barras en las columnas indican la desviación estándar de tres repeticiones por tratamiento para $\mathrm{P}<0.05$.

Figure 2. Effect of soaking, use of spices (bay leaf and epazote), and cooking method (pressure cooker or clay), on the concentration of a-galactooligosaccharides raffinose and stachyose in 'Pinto Saltillo' beans (mg/g dry base). Bars indicate the standard deviation of three repetitions per treatment for $\mathrm{P}<0.05$.

los oligosacáridos hace que sea posible su eliminación a través del remojo de las leguminosas (Serna-Cock et al., 2019; Njoumi et al., 2019) por lo tanto, la práctica de remojo antes de la cocción, en sus diferentes variantes, no solo ayuda a la cocción más rápida de sus granos sino que también mejora sus cualidades nutricionales a través de la disminución del contenido de oligosacáridos rafinosa y estaquiosa.

En aquellos tratamientos sin remojo, el efecto tanto del método de cocción como del uso de especias fue considerablemente significativo en la disminución de oligosacáridos $(\mathrm{P}<0.05)$. Sin previo remojo, el frijol cocido en olla de barro mostró una considerable reducción en la concentración de rafinosa y estaquiosa, en comparación con la cocción en olla a presión; sugiriendo que un tiempo prolongado de cocción disminuye la concentración de estos oligosacáridos (Figura 2). Esto concuerda con lo reportado por lyer et al. (1980) quienes 
encontraron una menor concentración de oligosacáridos en frijoles sometidos a cocción por 90 min en comparación con una cocción por $15 \mathrm{~min}$. Njoumi et al. (2019) encontraron una considerable disminución de rafinosa y estaquiosa en lentejas, garbanzos y habas, después de un periodo de cocción de $1 \mathrm{~h}$ a temperatura de ebullición, atribuyendo este efecto a la activación de enzimas a-galactosidasas inherentes en las leguminosas, las cuales encuentran condiciones óptimas a esta temperatura.

La cocción con presión sin remojo mostró la mayor concentración de a-galacto-oligosacáridos y es aquí donde se puedo observar el efecto de las especias, en donde tanto el epazote como el laurel lograron una considerable disminución en la concentración de rafinosa y estaquiosa $(P<0.05)$ (Figura 2). Estos resultados muestran la importancia del uso de especias en la cocción del frijol, cuando este no es sometido a un previo remojo.

La reducción de rafinosa y estaquiosa en frijol mediante la aplicación de las especias (epazote y laurel) (Figura 2), es un resultado científico importante que sustenta la tradición cultural de México, del uso de especias para evitar las flatulencias. Comprobando el criterio de los antepasados mexicanos dada la disminución de esos compuestos que comúnmente están relacionados con la producción de gases a nivel intestinal. Resaltando la importancia de rescatar las tradiciones que se pierden en el tiempo por la adopción de prácticas culinarias que facilitan la preparación de los alimentos pero que pueden disminuir su valor alimenticio.

No existe fundamento hasta el momento, que explique cómo el uso de estas especias disminuye el contenido de rafinosa y estaquiosa, se sugiere la presencia de a-galactosidasas en ambas plantas, epazote y laurel; con una mayor actividad de esta enzima en las hojas de laurel, dado que se observa una mayor disminución de oligosacáridos con el uso de esta especia (Figura 2). Cabe señalar que no se han realizado estudios relacionados con esto, lo cual lleva a seguir supuestos teóricos que podrían significar una importante fuente de futuras investigaciones. Enzimas a-galactosidasas han sido encontradas en hojas de cebada (Chrost et al., 2004; Chrost et al., 2007), en tallos de caña de azúcar (Chinen et al., 1981), en la planta del melón (Chrost y Schmitz, 2000), en hojas de calabacines (Gaudreault y Webb, 1982; Gaudreault y Webb, 1983) , así como en hojas de espinaca (Gatt y Baker, 1979).

\section{Inhibidor de trispsina}

En cuanto al Inhibidor de tripsina se pudo apreciar que el remojo y la cocción afectaron, significativamente $(P<0.05)$ el contenido de este factor antinutricional lo cual no sucedió con las especias ya que no hubo diferencias estadísticamente significativas. Sin embargo, las interacciones remojo-cocción, especia-cocción y la triple interacción remojo-especiacocción mostraron también diferencias estadísticamente significativas.

En el análisis de los factores que mostraron interacción (Figura 3) se pudo apreciar porcentajes de reducción entre 94.52 y $98.82 \%$ para los tratamientos cocción en barro

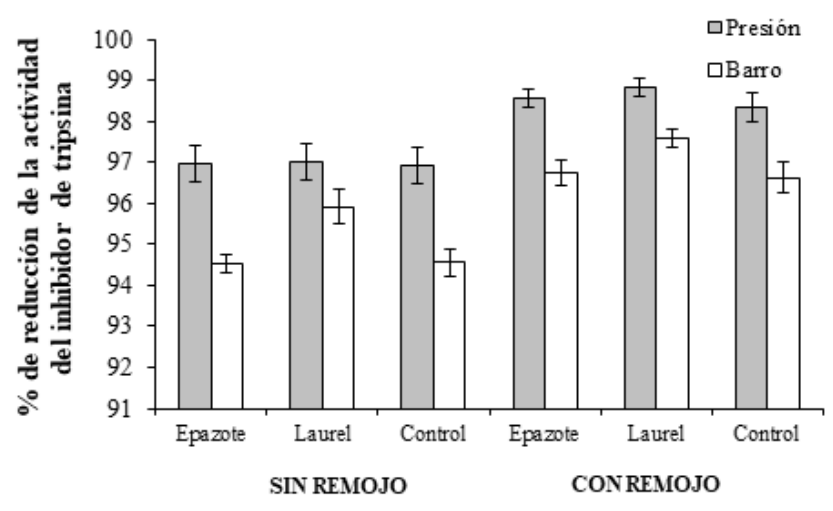

Figura 3. Efecto del remojo, uso de especias (laurel y epazote) y método de cocción (olla a presión o de barro), en la reducción de la actividad del inhibidor de tripsina (\%) en frijol 'Pinto Saltillo' ( $\mathrm{mg} / \mathrm{g}$ base seca). Las barras en las columnas indican la desviación estándar de tres repeticiones por tratamiento para $\mathrm{P}<0.05$.

Figure 3. Effect of soaking, use of spices (bay leaf and epazote), and cooking method (pressure cooker or clay), on the reduction of the trypsin inhibitor activity (\%) in beans 'Pinto Saltillo'. Bars indicate the standard deviation of three repetitions per treatment for $\mathrm{P}<0.05$.

sin remojo y sin especias y cocción en presión con la especia laurel y con remojo, respectivamente. La cocción en presión por si sola es capaz de reducir el inhibidor de tripsina en mayor cantidad que la olla de barro, pero la cocción con presión y remojo previo por $12 \mathrm{~h}$ es aún más efectiva en la reducción de este factor antinutricional que la presión sin remojo. Corzo-Ríos et al. (2020) encontraron una pérdida del $100 \%$ de la actividad de los inhibidores de tripsina, después del tratamiento térmico bajo presión por 45 minutos. De acuerdo con Corzo-Ríos et al. (2020), los inhibidores de tripsina son proteínas termolábiles que se desnaturalizan durante los tratamientos térmicos de cocción del frijol, perdiendo su actividad.

La reducción del inhibidor de tripsina, mediante tratamientos térmicos, ha sido un aspecto ampliamente estudiado debido que estas enzimas disminuyen la actividad de las enzimas proteasa y reducen la digestibilidad de la proteína bruta (PB) y de los aminoácidos (de Coca-Sinova et al., 2008; Valencia et al., 2008) por lo que, mediante estos tratamientos se logran un mayor aprovechamiento de las proteínas que contienen las leguminosas.

Se ha señalado que los tratamientos térmicos y el remojo previo son capaces de reducir este factor antinutricional, en gran medida, en varias especies de leguminosas. La reducción de este factor antinutricional consecuencia de un remojo previo puede deberse a la solubilidad del inhibidor de tripsina que le permite su migración de la semilla al medio de remojo.

Varios autores (Hernández and Escuerdo, 1993; Bilbao et al., 2000) han informado que la cocción y el remojo son capaces de reducir este antinutriente en frijol. Barampama y Simard (1994) encontraron una reducción de $97.78 \%$ al remojar los frijoles y utilizar cocción tradicional. Sin embargo, en esta investigación se encontraron mayores porcentajes de 
reducción del inhibidor de tripsina cuando se coció el frijol en olla a presión luego de ser remojado por $12 \mathrm{~h}(98.3 \%$ de reducción), al cocer el frijol en presión con la adición de laurel luego del remojo (98.8\%) y al cocer el frijol en presión con la especia epazote luego del remojo (98.5\%).

Así mismo, Egounlety y Aworh (2003) han informado de la reducción de este antinutriente con remojo y cocción en leguminosas de importancia económica como la soya (Glycine max Merr.), Caupí (Vigna unguiculata L. Walp) y frijol molido (Macrotyloma geocarpa Harms) y en guisante (Pisum sativum L.) (Ma et al., 2018), Sin embargo, no existen reportes de la disminución del inhibidor de tripsina comparando la cocción en olla de presión y en olla de barro en frijol común.

Así mismo, hasta la fecha no existen reportes de la reducción del inhibidor de tripsina en frijol común cuando se combinan la cocción con las especias epazote y laurel lo que es relevante dado que se combinan la forma de preparación que más se usa en la actualidad con las especias que tradicionalmente se han empleado en la preparación de este grano.

\section{Crecimiento microbiano}

La Figura 4 muestra el efecto del uso de olla de barro versus olla a presión sobre el crecimiento microbiano psicrotrófico durante el almacenamiento de frijoles. Existe un mayor efecto de inhibición microbiana cuando se usa presión en comparación con la olla de barro (Figura 4B). Esto podría deberse al mayor efecto de inhibición microbiana de la alta temperatura de cocción utilizada en la olla a presión (121ํㅡ).

El efecto de la inhibición psicrotrófica microbiana debido a la adición de laurel y epazote se muestra en la Figura 4. El día 1, para olla a presión, y los días 1 y 2 para olla de barro, no se observó inhibición microbiana, incluso una inhibición negativa en los frijoles, es decir un incremento en la población bacteriana. Esto podría atribuirse al hecho de que las hojas de laurel y epazote fueron agregadas sin lavado previo y sin sanitización, y es sabido que las especias pueden ser una importante fuente de contaminación microbiana (McKee, 1995). A pesar de esto, posteriormente, se observó una inhibición microbiana psicrotrófica significativa en frijoles que contienen laurel y epazote durante el almacenamiento. Algunos autores han encontrado una alta actividad antifúngica de las hojas de laurel y de epazote (Akdemir Evrendilek, 2015; Erenpreiss et al., 2006; Suhr and Nielsen, 2003).

El uso tradicional de epazote y laurel para cocinar frijoles, y el método de cocción afectaron la calidad microbiana durante el almacenamiento. Los frijoles con epazote y laurel exhibieron inhibición psicrotrófica microbiana, a partir del día 2 de refrigeración (Figura 4). El efecto inhibitorio del laurel fue más pronunciado en el tratamiento de cocción en olla de presión, mientras que el epazote tuvo un mayor efecto inhibitorio cuando el frijol fue sometido a cocción en olla de barro. Los tratamientos a presión mostraron menores cargas microbianas en todo momento durante el almacenamiento en comparación con los tratamientos de barro (Figura 4).
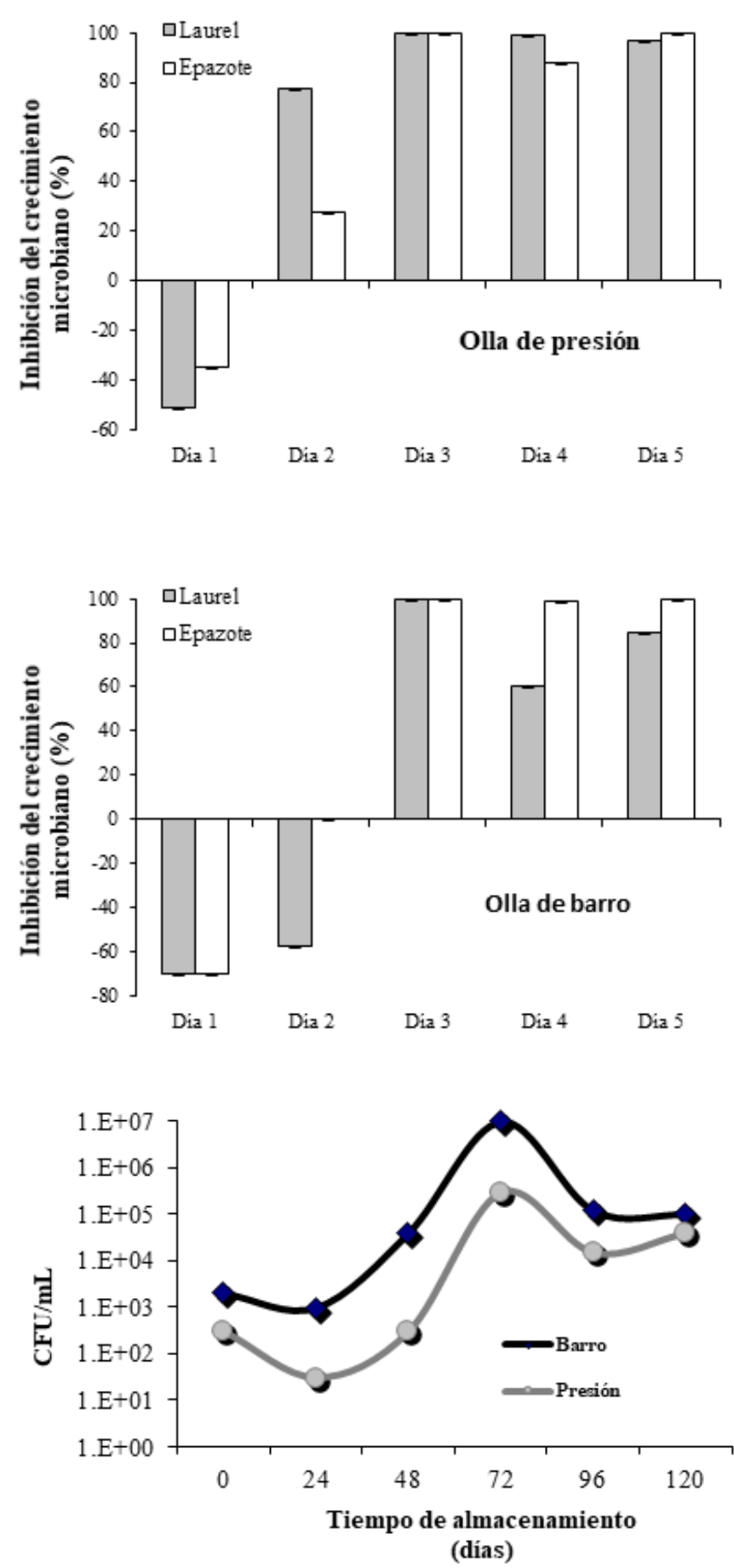

Figura 4. Inhibición del crecimiento de bacterias psicotróficas, durante el almacenamiento a $4^{\circ} \mathrm{C}$ durante 5 días, de frijol 'Pinto Saltillo' cocinado en olla a presión o en olla de barro, con la adición de epazote o laurel (A), y sin la adición de especias (B).

Figure 4. Psychotropic bacteria inhibition during storage at $4{ }^{\circ} \mathrm{C}$ for 5 days, of 'Pinto Saltillo' beans cooked in a pressure cooker or a clay pot, with the addition of epazote or bay leaf (A), and without the addition of spices (B). 


\section{CONCLUSIONES}

Los métodos tradicionales de preparación del frijol empleando laurel y epazote favorecieron la reducción los factores antinutricionales, especialmente los oligosacáridos, así mismo incrementaron la vida de anaquel al inhibir el crecimiento microbiano. Sin embargo, estas especias no tuvieron un efecto significativo en la disminución de ácido fítico. Para una mayor disminución de los factores antinutricionales y una mayor inhibición microbiana la cocción bajo presión con previo remojo y el uso de especias, en especial el laurel, fueron la mejor opción al exhibir mejores resultados. Para el caso de cocción en olla de barro, igualmente se recomienda el remojo previo así como el uso de especias, principalmente epazote. El uso de especias en la cocción del frijol con el objetivo de disminuir el contenido de oligosacáridos causantes de flatulencias, que por tradición, aunque sin fundamento científico, se ha utilizado en México, con el presente trabajo se sustenta. Esto nos lleva a pensar en la importancia de evaluar las tradiciones culinarias mexicanas para evitar que estas se pierdan antes de conocer y sustentar su importancia. Los resultados obtenidos en este estudio muestran la importancia de evaluar el uso de las tradiciones culinarias de México con la finalidad de preservarlas y resaltar su valor.

\section{BIBLIOGRAFÍA}

Aguilera, Y., Martín-Cabrejas, M. A., Benítez, V., Mollá, E., LópezAndréu, F. J. y Esteban, R. M. 2009. Changes in carbohydrate fraction during dehydration process of common legumes. Journal of Food Composition and Analysis, 22: 678-683.

Akdemir Evrendilek, G. 2015. Empirical prediction and validation of antibacterial inhibitory effects of various plant essential oils on common pathogenic bacteria. International Journal of Food Microbiology, 202:35-41.

Al-Kaisey, M. T., Alwan, A.-K. H., Mohammad, M. H. y Saeed, A. H. 2003. Effect of gamma irradiation on antinutritional factors in broad bean. Radiation Physics and Chemistry, 67: 493-496.

Alonso, R., Aguirre, A. y Marzo, F. 2000. Effects of extrusion and traditional processing methods on antinutrients and in vitro digestibility of protein and starch in faba and kidney beans. Food Chemistry, 68: 159-165.

Armendáriz-Fernández, K. V., Herrera-Hernández, I. M., MuñozMárquez, E. y Sánchez, E. 2019. Characterization of bioactive compounds, mineral content, and antioxidant activity in bean varieties grown with traditional methods in Oaxaca, Mexico. Antioxidants, 26: 1-17.

Barampama, z. y Simard, R. E. 1994. Oligosaccharides, antinutritional factors, and protein digestibility of dry beans as affected by processing. Journal of Food Science, 59: $833-$ 838.

Beleia, A., Thu Thao, L. y Ida, E. I. 1993. Lowering phytic phosphorus by hydration of soybeans. Journal of Food Science, 58: 375-377.

Bilbao, T., Hampe, S., Smith, R., Puerta, F. y Ledesma, L. 2000. Presence of antinutritional factors and natural toxins in coloured beans (Phaseolus vulgaris L.) and peas (Pisum sativum L.) during storage at room temperature. Alimentaria, 37: 147-150.
Carter, C. E. y Manthey, F. A. 2019. Seed treatments affect milling properties and flour quality of black beans (Phaseolus vulgaris L.). Cereal Chemistry, 96: 689-697.

Chávez-Mendoza, C., Hernández-Figueroa, K. y Sánchez, E. 2019. Antioxidant Capacity and Phytonutrient Content in the Seed Coat and Cotyledon of Common Beans (Phaseolus vulgaris L.) from Various Regions in Mexico. Antioxidants, 8: 1-19.

Chinen, I., Nakamura, T. y Fukuda, N. 1981. Purification and properties of a-galactosidase from immature stalks of Saccharum officinarum (sugar cane). The Journal of Biochemistry, 90: 1453-1461.

Chrost, B., Daniel, A. y Krupinska, K. 2004. Regulation of a-galactosidase gene expression in primary foliage leaves of barley (Hordeum vulgare L.) during dark-induced senescence. Planta, 218: 886-889.

Chrost, B., Kolukisaoglu, U., Schulz, B. y Krupinska, K. 2007. An a-galactosidase with an essential function during leaf development. Planta, 225: 311-320.

Corzo-Ríos, L. J., Sánchez-Chino, X. M., Cardador-Martínez, A., Martínez-Herrera, J. y Jiménez-Martínez, C. 2020. Effect of cooking on nutritional and non-nutritional compounds in two species of Phaseolus ( $P$. vulgaris and $P$. coccineus) cultivated in Mexico. International Journal of Gastronomy and Food Science, 20: 1-7.

De Coca-Sinova, A., Valencia, D., Jiménez-Moreno, E., Lázaro, R. y Mateos, G. G. 2008. Apparent ileal digestibility of energy, nitrogen, and amino acids of soybean meals of different origin in broilers. Poultry Science, 87: 2613-2623.

Egounlety, M. y Aworh, O. C. 2003. Effect of soaking, dehulling, cooking and fermentation with Rhizopus oligosporus on the oligosaccharides, trypsin inhibitor, phytic acid and tannins of soybean (Glycine max Merr.), cowpea (Vigna unguiculata L. Walp) and groundbean (Macrotyloma geocarpa Harms). Journal of Food Engineering, 56: 249-254.

Erenpreiss, J., Spano, M., Erenpreisa, J., Bungum, M. y Giwercman, A. 2006. Sperm chromatin structure and male fertility: biological and clinical aspects. Asian Journal of Andrology, 8: 11-29.

Escalante-Estrada, J. A. S., Rodríguez-González, M. T. y EscalanteEstrada, Y. I. 2014. Tasa de crecimiento de biomasa y rendimiento de frijol en función del nitrógeno. Ciencia y tecnología agropecuaria de México, 2: 1-8.

Eskin, N. M. y Wiebe, S. 1983. Changes in phytase activity and phytate during germination of two fababean cultivars. Journal of Food Science, 48: 270-271.

Gatt, S. y Baker, E. A. 1970. Purification and separation of aand $\beta$-galactosidases from spinach leaves. Biochimica et Biophysica Acta (BBA) - Enzymology, 206: 125-135.

Gaudreault, P.-R. y Webb, J. A. 1983. Partial purification and properties of an alkaline a-galactosidase from mature leaves of Cucurbita pepo. Plant Physiology, 71: 662-668.

Gaudreault, P. R. y Webb, J. A. 1982. Alkaline a-galactosidase in leaves of Cucurbita pepo. Plant Science Letters, 24: 281-288.

Gomes Basso Los, F., Zielinski, A. A. F., Wojeicchowski, J. P., Nogueira, A. y Demiate, I. M. 2018. Beans (Phaseolus vulgaris L.): whole seeds with complex chemical composition. Current Opinion in Food Science, 19: 63-71.

Grewal, A. y Jood, S. 2006. Effect of processing treatments on nutritional and antinutritional contents of green gram. Cereal Chemistry, 30: 535-546. 
Hamerstrand, G., Black, L. y Glover, J. 1981. Trypsin inhibitors in soy products: modification of the standard analytical procedure. Cereal Chemistry, 58: 42-45.

Hayat, I., Ahmad, A., Masud, T., Ahmed, A. y Bashir, S. 2014. Nutritional and health perspectives of beans (Phaseolus vulgaris L.): an overview. Critical reviews in food science and nutrition, Critical Reviews in Food Science and Nutrition, 54: 580-592.

Hernández, C. J. y Escuerdo, A. C. J. A. M. 1993. Efecto de la cocción sobre algunas características nutricionales del frijol. Agronomía Mesoamericana, 4: 42-47.

lyer, V., Salunkhe, D., Sathe, S. y Rockland, L. B. J. P. F. f. H. N. 1980. Quick-cooking beans (Phaseolus vulgaris L.): II. Phytates, oligosaccharides, and antienzymes. Qualitas Plantarum Plant Foods Human Nutrition, 30:45-52.

Jood, S., Mehta, U., Singh, R., Bhat, C. M. 1985. Effect of processing on flatus-producing factors in legumes. Journal of Agricultural and Food Chemistry, 33: 268-271.

Kon, S. J. J. o. F. S. 1979. Effect of soaking temperature on cooking and nutritional quality of beans. Journal of Food Science, 44:1329-1335.

Leyva Trinidad, D. A. y Pérez Vázquez, A. 2015. Pérdida de las raíces culinarias por la transformación en la cultura alimentaria. Revista Mexicana de Ciencias Agrícolas, 6: 867881.

Lo Turco, V., Potortì, A. G., Rando, R., Ravenda, P., Dugo, G. y Di Bella, G. 2016. Functional properties and fatty acids profile of different beans varieties. Natural Product Research, 30: 2243-2248.

Ma, Z., Boye, J. I. y Hu, X. J. L. 2018. Nutritional quality and technofunctional changes in raw, germinated and fermented yellow field pea (Pisum sativum L.) upon pasteurization. Food Science and Technology, 92: 147-154.

Machaiah, J. P. y Pednekar, M. 2002. Carbohydrate composition of low dose radiation-processed legumes and reduction in flatulence factors. Food Chemistry, 79: 293-301.

McKee, L. H. 1995. Microbial contamination of spices and herbs: A review. LWT - Food Science and Technology, 28: 1-11.

Meléndez Torres, J. M. y Cañez De la Fuente, G. M. 2009. La cocina tradicional regional como un elemento de identidad y desarrollo local: el caso de San Pedro El Saucito, Sonora, México. Estudios Sociales (Hermosillo, Son.), 17:181-204.

Njoumi, S., Josephe Amiot, M., Rochette, I., Bellagha, S. y Mouquet-Rivier, C. 2019. Soaking and cooking modify the alpha-galacto-oligosaccharide and dietary fibre content in five Mediterranean legumes. International Journal of Food Sciences and Nutrition, 70: 551-561.

Parmar, N., Singh, N., Kaur, A. y Thakur, S. 2017. Comparison of color, anti-nutritional factors, minerals, phenolic profile and protein digestibility between hard-to-cook and easy-tocook grains from different kidney bean (Phaseolus vulgaris) accessions. Journal of Food Science and Technology, 54: 1023-1034.
Pérez-Ramírez, I. F., Becerril-Ocampo, L. J., Reynoso-Camacho, R., Herrera, M. D., Guzmán-Maldonado, S. H. y Cruz-Bravo, R. K. 2018. Cookies elaborated with oat and common bean flours improved serum markers in diabetic rats. Journal of the Science of Food and Agriculture, 98: 998-1007.

Rehman, Z.-u. y Shah, W. 2005. Thermal heat processing effects on antinutrients, protein and starch digestibility of food legumes. Food Chemistry, 91: 327-331.

Revilla, I. 2015. Chapter 40 - Impact of Thermal Processing on Faba Bean (Vicia faba) Composition. Processing and Impact on Active Components in Food, 337-343.

Sánchez-Mata, M. C., Peñuela-Teruel, M. J., Cámara-Hurtado, M., Díez-Marqués, C. y Torija-Isasa, M. E. 1998. Determination of mono-, di-, and oligosaccharides in legumes by highperformance liquid chromatography using an aminobonded silica column. Journal of Agricultural and Food Chemistry, 46. 3648-3652.

Serna-Cock, L., Pabón-Rodríguez, O. V. y Quintana-Moreno, J. D. 2019. Efectos de la fuerza iónica y el tiempo de remojo de legumbres secas sobre sus propiedades tecnofuncionales. Información Tecnológica, 30: 201-210.

Shimelis, E. A. y Rakshit, S. K. 2007. Effect of processing on antinutrients and in vitro protein digestibility of kidney bean (Phaseolus vulgaris L.) varieties grown in East Africa. Food Chemistry, 103: 161-172.

Suhr, K. I. y Nielsen, P. V. 2003. Antifungal activity of essential oils evaluated by two different application techniques against rye bread spoilage fungi. Journal of Applied Microbiology, 94: 665-674.

Talari, A., Shakappa, D. 2018. Effect of Domestic Processing and Crude Extract of a-Galactosidase on Oligosaccharide Content of Red Gram (Cajanus cajan L.) Seeds. Current Research in Nutrition and Food Science, 6: 852-861.

Udensi, E., Ekwu, F. y Isinguzo, J. J. 2007. Antinutrient factors of vegetable cowpea (Sesquipedalis) seeds during thermal processing. Pakistan Journal of Nutrition, 6: 194-197.

Ulloa, J. A., Rosas Ulloa, P., Ramírez Ramírez, J. C. y Ulloa Rangel, B. E. 2011. El frijol (Phaseolus vulgaris): su importancia nutricional y como fuente de fitoquímicos. Revista Fuente, 3: 5-9

Valencia, D., Serrano, M., Lázaro, R., Latorre, M., Mateos, G. J. 2008. Influence of micronization (fine grinding) of soya bean meal and fullfat soya bean on productive performance and digestive traits in young pigs. Animal Feed Science and Technology, 147: 340-356.

Wang, N., Hatcher, D. W., Tyler, R. T., Toews, R. y Gawalko, E. J. 2010. Effect of cooking on the composition of beans (Phaseolus vulgaris L.) and chickpeas (Cicer arietinum L.). Food Research International, 43. 589-594.

Xu, B. y Chang, S. K. 2009. Total phenolic, phenolic acid, anthocyanin, flavan-3-ol, and flavonol profiles and antioxidant properties of pinto and black beans (Phaseolus vulgaris L.) as affected by thermal processing. Journal of Agricultural and Food Chemistry, 57: 4754-4764. 